\title{
A Framework to Support Development of Learning Applications for Disabled Children
}

\author{
José L. Fuertes ${ }^{1}$, Ángel L. González ${ }^{1}$, Gonzalo Mariscal ${ }^{2}$, and Carlos Ruiz ${ }^{2}$ \\ ${ }^{1}$ Facultad de Informática, Universidad Politécnica de Madrid, \\ Boadilla del Monte, Madrid. Spain \\ \{jfuertes, agonzalez\} afi.upm. es \\ ${ }^{2}$ GI-CETTICO. Universidad Politécnica de Madrid. Boadilla del Monte. Madrid, Spain \\ \{gmariscal, cruiz\} @ecttico.fi.upm.es
}

\begin{abstract}
Multimedia resources are an important tool that can be used by teachers in the classroom as a learning aid for leamers with disabilities or by parents and children at home. However, disabled children are not always able to use existing assistive technologies because they are not experienced enough, suffer from medium/profound disability, or simply do not have the financial resources to buy commercial tools. Additionally, today's adapted tools are not always valid for a broad spectrum of disabled users and often focus on a user group. We claim that potential applications and resources for people with special needs must self-adapt to user capabilities and skills. reducing the use of extemal assistive technologies. In this paper. we present a guide for developers to create accessible applications and resources that reduce workload.
\end{abstract}

Keywords: Accessibility, human-computer interaction. education. assistive technology, children, special educational needs.

\section{Introduction}

The term 'special educational needs' (SEN) refers to people with learning difficulties or disabilities that make it harder for them to learn or access education than their peers [1]. Teaching SEN pupils is a complex task which involves implementing a teaching process and providing access to materials suited to learners' skills. In this context, digital media are a very useful tool to exploit in the classroom to educate SEN pupils.

The standards and guidelines for accessible software and Internet contents [2], [3] describe how applications should work to be used by disabled people with alternative devices and assistive technologies (ATs). The use of these standards benetits all users, as it equips systems for use by a broad spectrum of users.

There are several AT tools that can be used to adapt computer programs for people with special needs. They can be hardware or software based, and equally as wideranging and diverse as learners' capabilities and levels, and applications are. The selection of the best technology calls for a thorough and complex decision-making process to assure proper and effective use by each learner [4].

Moreover, an important consideration is that some ATs are complicated, difficult to set up and to learn. A non-proficient user may find it difficult to use ATs effectively 
or to combine a set of ATs. But what happens when the user is a child that has not yet learned how to use ATs like, for example, a screen reader or Braille display?

A lot of adapted tools reduce the development workload by just using ATs designed for a particular user type, even though multimedia tools only partially support some accessibility features. This decreases the number of potential users.

In this context, apart from conforming to the above standards, we claim that, despite the huge workload involved in developing a self-adaptive application, applications for SEN people should at least partially self-adapt to user capabilities and skills in order to improve use inexperienced AT users and solve this problem [4].

At first glance, managing all the alternatives suited to each user looks to be a complicated undertaking. We propose a development model and a framework to reduce the development workload of accessible self-adaptive applications.

Some of the features detined in the model and implemented in the current version of the framework are: indistinct use of mouse and keyboard, alternative text exposed to ATs for all graphical elements, descriptive text for all images, multilingual support, definition of direct accesses for each interactive system element, improving keyboardmediated use and the use of concept keyboards, synchronized subtitling...

The remainder of the paper is organized as follows. In Section 2 we will look at existing solutions to the problem. In Section 3 we will present our solution and the platform implementation for Adobe Flash. Finally, in Section 4, we will present the results of applying the proposed Flash-based solution to a real-world problem.

\section{State of the Art}

Noteworthy tools with educational contents for children with SEN are "Hércules and Jil6" [5], CompuThera [6], "My Own Bookshelf" and "Running Start Books - Social Scripts"1 [7]. E-learning software to help Down syndrome children to learn basic mathematical concepts and skills is described in [8].

Multimedia content is now a lot easier to author thanks to new tools, which have added the option of providing variable accessibility levels. US guideline-compliant accessible multimedia applications have been developed using Macromedia Flash MX since 2005. The Adobe Flash API offers a number of basic accessibility reatures, enabling communication with Microsoft Active Accessibility, but there are still accessibility gaps requiring programming or purchasing from another supplier [9].

Microsoft Silverlight [10] is a web application framework that offers a wide range of new accessibility enhancements: tabbing and tab order, focus and keyboard input, exposed Accessibility Tree for ATs, accessibility information written directly in XAML, notifications for high-contrast requirements...

Other approaches focus on adaptive course generation and adaptive e-learning platforms (Diogene and Intraserv [11], CEPIAH [12], eMEMORA [13]...). These generate contents automatically taking into account some metadata related to student profiles. The main weaknesses of these platforms are that a user profile has to be entered beforehand, and teachers have to provide a lot of information about all users.

\footnotetext{
${ }^{1}$ http:/www.softtouch.com
} 
Interactive multimedia authoring tool developers are investing a lot in improving the authoring of accessible materials. But all these tools come up short when users do not know how to use or cannot use some ATs. This applies to children with SEN, who, for age-related reasons, are unable to use some of the ATs recommended for users with a particular disability. For example, one pedagogical recommendation is to use recorded voices rather than screen readers with voice synthesis [14].

\section{Proposed Solution}

The solution is composed of a guide specifying the steps to be taken by the developer, including an implementation for the specific platform using the framework [15], [9].

\subsection{Developing Steps}

This phase is carried out during system design and analysis. Fig. 1 shows the required steps. The process starts after analysing the application. The first step is to define scenes. Scenes state a setting for interaction that is useful for establishing the right representation for each element and, in the case of educational resources, helps to define outcome assessment processes. It also improves the correlation between each scene and the learning objectives it addresses.

The next step is to analyse the interaction process and define a script for each scene. This step sets out a description of how to implement the interaction with the user.

The following step is to analyse the scripts. This analysis is helpful for determining the "actors" (interactive objects) and defining the actions that the user will be able to take, as well as useful information for understanding the scene (informational objects).

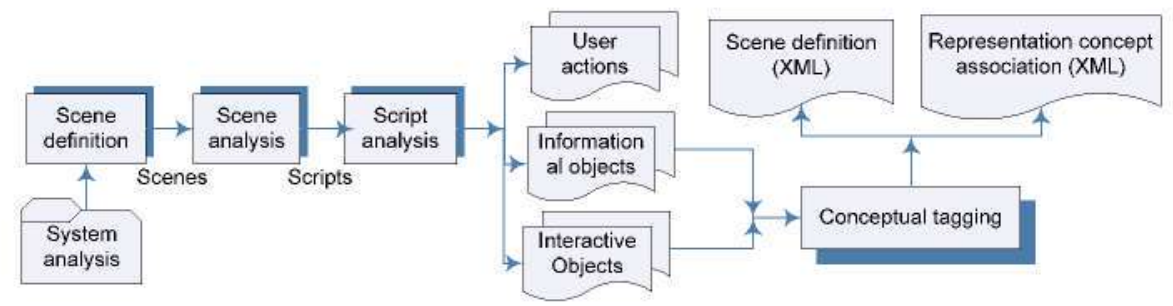

Fig. 1. Steps prior to framework use

The last step is conceptual tagging which enables the framework to represent and locate the materials required to render the scene, taking into account parameters like language, language proficiency, user abilities, etc. It associates a concept or identifier representing an element's purpose (interactive object, informational object, user action) to each input element within a scene. Also an XML document containing the relationship between the concept and its representation is generated [16].

\subsection{The Model and Its Framework for Flash}

The proposed solution models levels of conceptual abstraction [16]: conceptual definition of user actions, and of the interactive object and informational object. 


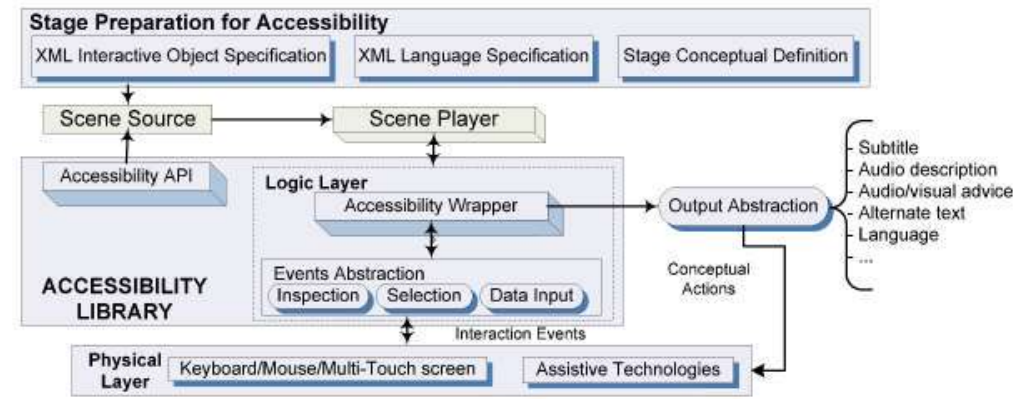

Fig. 2. Architecture overview

The mechanisms required to translate the AT input to a conceptually defined action or for use in system-user communications are provided by the Flash framework. The association of each interactive object and its scene with conceptual information enables this translation.

The defined model is shown in Fig. 2. Scene Player and Scene Source represent the scene player (in the model implementation for Adobe Flash 9.0) and the source code contains the scene implementation.

We described the Stage Preparation for Accessibility in the last section. The goal of the Scene Preparation for Accessibility is to generate the required data in XML format for the Accessibility Library (AL) to be able to do translation jobs, build components and execute actions based on the behaviour of the actors (interactive objects) in the scene.

\subsection{Accessibility Library (AL)}

The AL's job is to automatically interpret the information it receives from the preparation stage. It uses this information to customize navigation and interaction with application objects. Programmers will receive support for specifying scene logic, whereas developers can access the Accessibility API. The four AL components are: Configuration Manager, Input/Output Manager, Context Manager and Language Manager [9].

\subsection{Abstraction Model}

Actions in response to user events are simplified by means of an abstraction adapted from the model described in [16]. The model will be responsible for associating each interactive object with the necessary events and translating user actions into the respective conceptual action. All this is transparent to developers: an API takes charge of applying the abstraction to the objects defined in the XML file. Developers only need to define conceptual actions, e.g. "Help", "Play", "Move object", etc., without bothering about how users request the execution of the action (click on a button, gesture, menu option selection, etc.) or what device they use (a qwerty keyboard, concept keyboard, pointing device, etc.).

Programmers have to use concepts that represent the output information transmitted to the user. XML files, created in the last stage, will contain the output information. The chosen configuration will determine the media to be used to display the information. 


\subsection{Output Abstraction}

This process is responsible for selecting the right media to represent the scene (Fig. 3). It requires user information, scene description and contextual information. This information is entered in the search engine to search for the required materials. The search engine uses a media repository. The media repository has been previously fed with the association between the concepts and representation defined in the preliminary 'Scene Definition' stage.

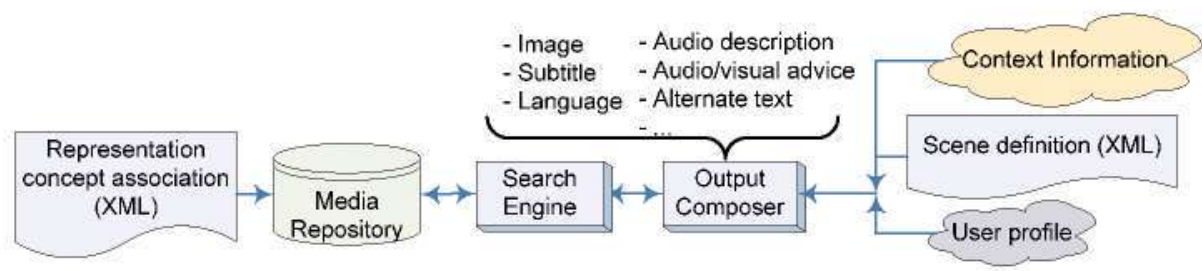

Fig. 3. Scene composition

As a result, the materials (image, audio description, descriptive text, etc.) required to represent the scene are assigned to the interactive objects and informational objects. The interactive objects and informational objects should also be registered as accessible elements. In the registration process, the information required for the scene to self adapt or be used with ATs, depending on user needs, is associated with these elements.

In our implementation for Adobe Flash 9, the search engine consists of an XML file set. The engine selects the XML file to extract the information based on the input parameters. Obviously, search engine complexity depends on problem requirements.

\section{Applying the Framework: Learn and Internet in the Classroom}

Based on this framework, we developed the Learn Project [15] and its continuation Internet in the Classroom ${ }^{2}$ [9] (Fig. 4), funded by the Spanish Ministry of Education and Science. These projects involve generating many accessible multimedia materials associated with a curriculum especially designed for learners with SEN. These activities are developed by subgroups working separately but liaising with each other. Development is coordinated by the Higher Institute of Teacher Training and Networked Resources. The CETTICO research group was responsible for developing some of these materials in both projects.

Both projects are online educational resources targeting children with learning difficulties. The overall objective is to build up and develop the physical, cognitive and communicational skills of learners with SEN using new ICT to promote their personal autonomy and social integration. To achieve the overall objective, it is necessary to attain other general goals such as introduce ICT at primary and secondary schools, develop modified curriculums to meet learners' needs, and develop accessible contents to help teachers in the classroom.

\footnotetext{
${ }^{2}$ http://www.educacontic.es/recursos
} 


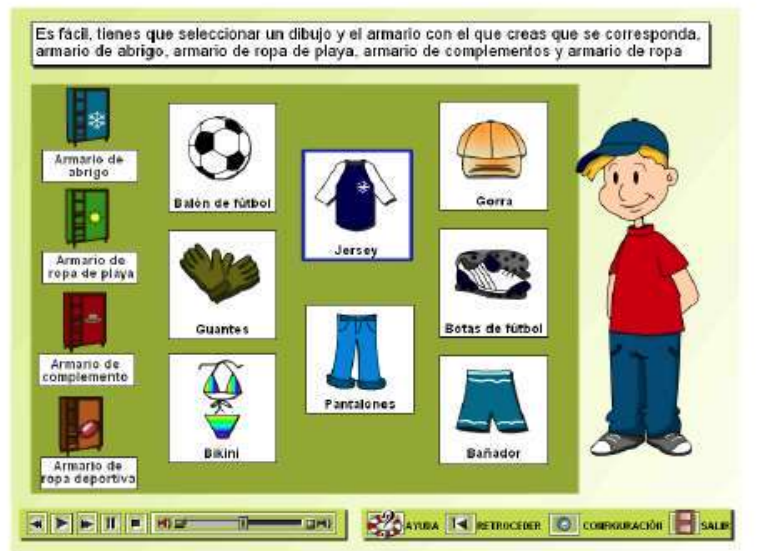

Fig. 4. Screenshot from Internet in the Classroom project

The projects imply the integration of different professional profiles with clearly defined tasks and responsibilities. Apart from the coordination team, three profiles were established: contents developers (pedagogues and educators), whose mission is to prepare the contents; graphics developers produce the graphics and audiovisual material; and technical developers (software engineers and programmers) who develop the new adaptive tools, design web pages and schedule activities.

These projects were developed taking into account the learners' needs and skills to customize the resource. Thus, other specific objectives related to learners' skills are:

- To establish multimedia activities related to personal autonomy, everyday problem solving and decision making.

- For pupils to learn to live in society through knowledge of the rules of cooperation and participation.

- To develop understanding, knowledge, linguistic skills, memory, logical reasoning and everyday problem-solving.

The learning objectives are metaphors (worlds, scenarios, characters or objects) to make the contents more appealing. They are learning worlds and their contents are:

1. Learning to be: It develops personal skills (dealing with feelings and tension...). Scenarios are presented as a number of interesting places visited in daily life.

2. Learning to do: This module develops practical skills in which learners apply their knowledge to interact with the environment and acquire new competences.

3. Learning to live together: This module develops interpersonal skills, pointing out learners' ability to interact and work in groups. These lessons also develop empathy, courtesy, friendship, cooperation and teamwork.

4. Learning to know: This module develops cognitive skills, such as decision making and problem solving.

The projects were implemented as a website (level AA of WCAG 1.0) and a multimedia application (conforming to the software accessibility standard [2]). 


\section{Results and Conclusions}

Educating people with SEN is a complex task even for experts and educators. Each learner's education should be individualized depending on his or her characteristics and abilities, enabling a more effective use of AT. Unfortunately, none of the previous research connects the whole teaching process.

The proposed solution takes into account all the steps in the teaching process for SEN (from design to implementation and evaluation). The presented model and its implementation for Adobe Flash 9 is able to reduce the workload involved in creating self-adaptive activities. To verify this point, we experimented on the 'Learn Project' and 'Internet in the classroom' taking measurements of the workload required to develop multimedia activities for groups with and without the technology described in this paper. We planned two experiments (see Table 1):

Table 1. Comparison of development times (days)

\begin{tabular}{ccc}
\hline Work Group & Use Case 1 & Use Case 2 \\
\hline Group 1 & 18.5 & 33.0 \\
Group 2 & 19.0 & 34.0 \\
CETTICO & 16.0 & 25.0 \\
Groups 1 \& 2 Average & 18.75 & 33.50 \\
\hline CETTICO Improvement & $15 \%$ & $25 \%$ \\
\hline
\end{tabular}

- Use Case 1: Development of an accessible learning object within the 'Learn' project. Development groups 1 and 2 each developed a very similar multimedia activity without using the tramework or the AL. The CETTICO group developed a similar activity to the other groups but using the framework and the AL.

- Use Case 2: Development of an accessible and self-adaptive learning object within the 'Internet in the Classroom' project. Development groups 1 and 2 developed a similar multimedia activity without using the framework or the AL. The CETTICO group developed a similar activity but using the framework and the $\mathrm{AL}$.

From the results in Table 1, we can conclude that our solution leads to a development workload reduction of about $15 \%$ for accessible applications and $25 \%$ if the application needs to be self adaptive. In addition, CETTICO developed 15 activities throughout the 2007-2008 project, of which 10 needed to be self-adaptive and the other five needed to be accessible and compatible with AT.

In order to assess the quality of results by accessibility and usability, the Spanish Ministry of Education's Institute of Educational Technologies (ISFTIC) applied an assessment process. The conclusion reached by ISFTIC is that the quality of accessibility and usability of the multimedia activities developed by the different teams was very similar. 


\section{References}

1. DirectGov: What are special educational needs?, http://ww direct.gov.uk/ en/Parents/Schoolslearninganddevelopment/

SpecialeducationalNeeds/DG_4008600

2. ISO (International Organization for Standardization): ISO 9241-171:2008 Ergonomics of human-system interaction - Part 171: Guidance on software accessibility (2008)

3. W3C: Web Content Accessibility Guidelines (WCAG) 2.0, http: / /WWW . W3 . org/TR/WCAG20

4. Poon-McBrayer, K.F., Lian. M.G.J.: Special needs education: children with exceptionalities. Chinese University Press (2002)

5. Lacerda, G.: Hércules y Jiló. Un Software Educativo para la Estimulación Matemática, Lingǘstica y Social de Niños con Deficiencia Mentas. Revista de Informática Educativa, 32-47 (Febrluary 2000)

6. Moore. M., Calvert, S.: Brief report: vocabulary acquisition for children with autism: teacher or computer instruction. Journal of Autism and Developmental Disorders, 359$362(2000)$

7. SoftTouch, http: //www. softtouch.com

8. Ortega-Tudela, J., Gómez-Ariza, C.: Computer assisted teaching and mathematical learning in Down syndrome children. Computers, Mathematics, and Down Syndrome 22. 298$307(2006)$

9. Cantón, P., González. Á.L.. Mariscal. G.. Ruiz. C.: Building accessible Flash applications: an XML-based toolkit. In: Miesenberger, K., Klaus, J.. Zagler, W.L.. Karshmer, A.I. (eds.) ICCHP 2008. LNCS, vol. 5105, pp. 370-377. Springer, Heidelberg (2008)

10. Rideout. M.: Accesibility in Silverlight 2. http://archive.visitmix.com/ blogs/Joshua/silverlight-2-Accessibility-with-Mark-Rideout/

11. Sangineto, E., Capuano, N., Gaeta. M., Micarelli, A.: Adaptive course generation through learning styles representation. Universal Access Information Society 7, 1-23 (2008)

12. Trigano, P.. Giacomini, E.: Toward a Web based environment for Evaluation and Design of Pedagogical Hypermedia. J. Educ. Technol. Soc. IEEE Learn. Technol. Task Force 7(3) (2004)

13. Benayache. A.. Abel. M.-H.: Using knowledge management method for e-learning. In: Chiazzese. G.. Allegra, M.. Chifari, A.. Ottaviano. S. (eds.) Methods and Technologies for Learning. WIT Press (2005)

14. Nass, C., Robles, E., Bienenstock. H.. Treinen, M., Heenan, C.: Voice-based disclosure systems: Effects of modality. gender of prompt, and gender of user. International Joumal of Speech Technology 6(2). 113-121 (2003)

15. Cantón. P., González. A.L., Mariscal, G., Ruiz, C.: Developing pedagogical multimedia resources targeting children with special educational needs. In: Miesenberger, K., Klaus. J., Zagler, W.L., Karshmer, A.I. (eds.) ICCHP 2006. LNCS, vol. 4061, pp. 536-543. Springer. Heidelberg (2006)

16. González, Á.L.: Modelo para la Generación y Gestión en Tiempo de Ejecución de Procesos de Interacción Hombre-Maquina a Partir de un Lenguaje de Especificación de Relaciones con el Usuario. PhD Thesis dissertation, Technical University of Madrid (2003), http: //oa. upm. es/87/ 